\title{
Educação Física: possibilidades de uma educação estético-ética
}

http://dx.doi.org/10.11606/1807-5509201900040649

\author{
Luísa Ávila da COSTA* \\ Teresa LACERDA*
}

*Faculdade

de Desporto,

Universidade do

Porto, Porto, Portugal.

\section{Resumo}

A aproximação à estética e à ética na investigação em filosofia do desporto tem por hábito abordar estas duas áreas filosóficas de forma distinta, separada e independente, sendo dada preponderância, por norma, aos trabalhos do âmbito da ética, que em volume marcam uma presença consideravelmente superior nas principais revistas internacionais deste campo de estudo. Estando o potencial pedagógico estético e ético do desporto amplamente descrito na literatura, o objetivo deste estudo prende-se com a procura das zonas de interface destes âmbitos numa abordagem estético-ética da educação física. 0 percurso metodológico seguido para a persecução deste objetivo integrou a recolha, análise e discussão, a partir de uma perspetiva hermenêutica e fenomenológica, dos discursos contidos em entrevistas semi-estruturadas de caráter exploratório, realizadas a um grupo de estudo que compreendeu dezanove professores/investigadores nas áreas da estética, da ética, do desporto e da educação física. 0 confronto do conteúdo proveniente das entrevistas com as reflexões já disponíveis sobre a temática na literatura permitiu-nos obter como resultado um roteiro argumentativo que explora o especial papel da educação física e a relevância da corporeidade na educação da sensibilidade estético-ética dos alunos no seu percurso escolar. Nas conclusões deste roteiro foram particularmente enfatizados quatro elementos com potencialidade estético-ética que contribuem para uma estético-ética do desporto recuperadora da unidade da experiência processo-produto no desporto. Esses elementos, que podem ser transportados do desporto para a vida no caminho do florescimento humano, foram a vulnerabilidade, a afetividade, a identidade e a competição.

Palavras-chave: Desporto; Educação Física; Estética; Ética; Estético-ética.

\section{Introdução}

A cultura anglo-saxónica reconhece no desporto ${ }^{a}$, por tradição e de forma explícita na literatura específica da área, um importante valor pedagógico estético e ético, nos processos formativos de crianças e jovens ${ }^{1-16}$. Vemos contudo, pelo menos em Portugal, uma progressiva desvalorização da disciplina de educação física nas escolas, quer pela gradual redução do seu tempo letivo, quer pela redução de qualquer impacto desta disciplina nas classificações médias finais letivas dos estudantes do ensino secundário, bem como no seu acesso ao ensino superior. Este aspeto contribui para que se encare com frequência a aula de educação física enquanto mero espaço de entretenimento e lazer e náo, necessariamente, de aprendizagem. No entanto, o desporto, e a natureza distinta desta disciplina relativamente à restante oferta escolar, apresenta um especial potencial pedagógico de virtualidades insubstituíveis ${ }^{17,18}$.

Grande parte dos professores de educação física que diariamente se encontram no terreno, testemunham uma predisposição natural da maioria das crianças para esta disciplina, por incorporar essa realidade de atração universal que é o desporto. Essa predisposição, que não pode ser desperdiçada, é muitas vezes defraudada devido a uma hipertrofia da educação cognitiva dos alunos no seu percurso escolar, a par da negligência de uma educação mais holística que a educação física, e até a educação artística, podem proporcionar ${ }^{13}$.

Uma visão humanista da educação física enquanto veículo de formação pluridimensional e integral do aluno deve, deste modo, contemplar preocupações axiológicas, entre as quais, as que remetem para 
os valores de belo e de bem, tradicionalmente associados à estética e à ética ${ }^{19,20}$.

Há algumas peculiaridades da disciplina de educação física que a tornam uma oportunidade especial e insubstituível de desenvolvimento estéticoético dos alunos ${ }^{2}$. Além de ser a única disciplina onde em termos motores os alunos se podem revelar de forma explícita, esta disciplina ocorre também num espaço que não é o espaço confinado de uma sala de aula, requerendo movimento dentro desse espaço. Talvez por este motivo, seja a única aula em que o aluno não pode iludir ou disfarçar a sua participação, algo que pode acontecer nas outras aulas. Numa aula de educação física ninguém se encosta, ou permanece em pausa, sentado, a dizer que sim com a cabeça e a pensar noutra coisa, sem ouvir nada. Isto significa que não só a amplitude do espaço e a necessidade de nele convivermos impóe exigências particulares de respeito e responsabilidade na partilha desse mesmo espaço entre os intervenientes, como também o envolvimento integral dos alunos na expressão de todas as suas capacidades os coloca numa situação de maior exposição, transparência e vulnerabilidade, que as restantes disciplinas não conseguem proporcionar. Deste modo, os processos de ensino/aprendizagem não se dão apenas verbal ou linguisticamente, mas são corporal e holisticamente experienciados. Abrem-se, assim, as portas a um modelo de educação pluridimensional, cuja inspiração remete para o modelo da paideia grega que, por não ter apenas como alvo pedagógico o desenvolvimento da mente, da virtude e do caráter, mas também, e de forma indivisível, da sensibilidade, da corporeidade e dos sentidos, remete para uma educação estético-ética ${ }^{18}$.

Neste sentido, é necessário que a educação física se afirme e, indo para além das preocupaçōes técnicas, assuma a responsabilidade do desenvolvimento de uma consciência estético-ética nos alunos, pelo desenvolvimento de competências não apenas motoras, mas também críticas, expressivas, contemplativas e criativas ${ }^{3,7}$. Porque, ao contrário da maioria das disciplinas escolares, trata do corpo como da mente, dos músculos como do raciocínio, da coordenação como da reflexão, da destreza motora como da perspicácia mental, da competência como da verdade de cada um, esta disciplina proporciona que os alunos desenvolvam a sua sensibilidade de forma holística e integral, na qual estética e ética se fundem e contaminam ${ }^{\mathrm{b}}$.

Enquanto espaço de aprendizagem onde a globalidade da pessoa está sempre atuante e é sempre relevante, o conteúdo desportivo proporciona um espaço pedagógico especial que põe a descoberto a importância da corporeidade na relação com o mundo e na aprendizagem humana ${ }^{25}$. A decrescente preponderância dada a esta disciplina em termos de espaço letivo nas escolas, pese embora o reconhecimento da sua pertinência na formação integral dos alunos, faz emergir a primazia do pensamento numa cultura tipicamente ocidental que ainda não leva a sério a indivisibilidade da pessoa no seu corpo e mente, ou na expressão de CUNHA E Silva, no seu corpo todo ${ }^{26}$.

Neste sentido, a ideia Merleau-Pontyana de enfatização da experiência corporal como criadora de sentidos da existência humana no mundo, sugerindo então que é pela corporeidade que melhor aprendemos, porque simplesmente somos corpóreos, possui uma relevante aplicabilidade na educação física que merece ser explorada ${ }^{27}$.

Despojando o pensamento da sua pretensão de soberania, a aprendizagem a partir da experiência corporal transforma o mero ato gnoseológico de conhecer o objeto de estudo, neste caso o desporto, numa experiência estético-ética da corporeidade, que é experiência de reconhecimento não só desse objeto, mas e sobretudo de nós mesmos.

Esta experiência estético-ética da corporeidade permite um caminho inverso de aprendizagem, no qual não são referenciais ou normativos externos que se impóem à aprendizagem corporal, mas uma corporeidade que, se a testarmos, explorarmos, ouvirmos e acolhermos, em si nos revela, ensina e, sobretudo, proporciona, uma experiência pedagógica corpórea estético-ética. Os artistas parecem ter já alcançado este entendimento, podendo citar-se a título de exemplo os realizadores Douglas Gordon e Philippe Parreno ${ }^{28}$, com o documentário cinematográfico "Zidane a TwentyFirst-Century Portrait", que pelo retrato do atleta na sua prática, revelado a partir de ângulos altamente focados na sua individualidade, procura convocar e sensibilizar o espetador para o permanente diálogo entre fisicalidade e pensamento, bem como pela escuta dos principais sinais vitais da corporeidade.

Neste sentido, o desporto é uma arena de eleição para a descoberta de conhecimentos, capacidades e potências às quais não teríamos acesso se não puséssemos a nossa corporeidade à prova, desenvolvendo a sensibilidade para a escutar.

Assim, a introdução à problemática sobre o especial papel da educação física na promoção de valores estéticos e éticos pode e deve ser feita, não 
só a partir do conteúdo proveniente de pontuais trabalhos de investigação nos domínios pedagógicos, mas também e sobretudo no dia-a-dia dos principais atores responsáveis por uma operacionalização da educação física ${ }^{16}$.

Deste modo, o objetivo principal da nossa pesquisa consistiu em aprofundar, a partir do contributo do nosso grupo de estudo, os elementos centrais da natureza especial da educação física que nos ajudam a compreendê-la e operacionalizá-la como veículo de uma educação mais holística e completa na qual, segundo argumentamos, os elementos estético-éticos assumem particular interesse.

Procurando penetrar as potencialidades estéticoéticas do desporto enquanto principal conteúdo da educação física, a reflexão sobre as zonas de entrecruzamento estético e ético na disciplina confluiu, neste trabalho, em argumentos em torno do desenvolvimento da sensibilidade do aluno através de uma experiência da corporeidade que

\section{Método}

A recolha de informação útil a uma abordagem hermenêutica e fenomenológica que colabore com o objetivo principal deste trabalho, isto é, uma perspetivação e compreensão da educação física enquanto veículo de uma estético-ética do desporto requer, pela sua natureza, percursos metodológicos de cariz qualitativo, que nos ajudem a compreender de que forma os principais atores sociais envolvidos neste problema de investigação refletem e configuram a sua própria realidade. Deste modo, procurando ir ao encontro do problema de investigação e realizar uma análise suficientemente compreensiva e indutiva do objeto de estudo ${ }^{29}$, o instrumento elegido para melhor aproveitar as potencialidades do nosso grupo de estudo, materializou-se na entrevista semi-estruturada de carácter exploratório, sendo a informação resultante da mesma tratada pelo método de análise temática de conteúdo ${ }^{30}$.

$\mathrm{O}$ processo de elaboração da entrevista passou por diferentes fases, tendo sido submetida a validação, quer ao nível da construção, quer ao nível do conteúdo, por um grupo de três investigadores com experiência na utilização deste tipo de instrumentos. Primeiramente foi elaborada uma versão piloto, que teve uma aplicação-teste em indivíduos com características permanece unitária entre processo e produto, entre razão e emoção, entre perceções, reflexões e sentimentos. Por conseguinte, a análise hermenêutica e fenomenológica da temática, cuja concretização se encontra explicada de forma mais detalhada no capítulo da metodologia, a partir dos discursos contidos nas entrevistas e o seu confronto com as reflexões já disponíveis sobre a temática na literatura, conduziu-nos a este itinerário argumentativo que aprofunda a pertinência da educação física e a relevância da corporeidade na educação da sensibilidade dos alunos no seu percurso escolar. Resultou desta análise um enredo reflexivo e argumentativo em torno de quatro elementos com potencialidade estético-ética que alimentaram a discussão sobre as possibilidades de uma estético-ética do desporto que aspira à recuperação da unidade da experiência processoproduto, são elas a vulnerabilidade, a afetividade, a identidade e a competição.

semelhantes ao grupo de participantes no estudo e, a partir do seu resultado e após os ajustamentos necessários, chegou-se à versão final. De seguida a entrevista foi submetida a validação por investigadores com experiência na utilização deste tipo de instrumento, para que finalmente pudesse ser aplicada ao grupo de estudo.

Porque não possuímos, nesta área de investigação ainda emergente, um mapeamento conceptual definido, e para que ele pudesse emergir como resultado deste trabalho, as categorias foram definidas tematicamente $a$ posteriori, e consubstancializadas na organização temática do artigo e nos elementos estético-éticos explorados.

Dado que no contexto do grupo de estudo incluímos indivíduos de quatro principais áreas distintas (ciências do desporto, filosofia, letras, belas artes e música), muito embora o guiāo base da entrevista fosse idêntico para todo o grupo, houve, todavia, margem para alguma especificidade no modo de abordar determinadas questões, no sentido de ir ao encontro e potenciar aquele que é o contributo específico de cada um dos diferentes olhares sobre a problemática. Procurou-se assim dar espaço a que os entrevistados informassem o problema de 
pesquisa de modo concreto e específico, tendo em vista uma recolha de dados mais rica e útil. Deste modo, foi nossa pretensão conseguir um equilíbrio entre uma relativa homogeneidade do grupo de estudo, que permitiu uma verdadeira triangulação e comparação da informação, mas simultaneamente uma significativa heterogeneidade que possibilitasse e conduzisse a uma abordagem suficientemente alargada e completa da temática.

\section{Participantes}

O grupo de estudo foi escolhido através de um critério específico, isto é, a representação dos principais atores sociais responsáveis ${ }^{31}$ por uma possível aplicação de uma formação estética e ética pelo desporto. Assim o grupo de participantes foi constituído por 19 entrevistados organizados em três sub-grupos distintos, designadamente: a) "Outside Sport Sciences", seis professores/investigadores dos âmbitos da educação estética e ética fora das ciências do desporto, que trabalhassem em áreas onde esta temática seja já tratada desde há muito tempo (arte, filosofia, teatro, música, dança, etc), designados ao longo do texto por OSS; b) "Inside Sport Sciences", sete professores/investigadores dentro das ciências do desporto cujo trabalho demonstrasse preocupações estéticas e éticas no âmbito da pedagogia e da educação pelo desporto, designados ao longo do texto por ISS; c) "Physical Education Teachers", seis professores de educação física, que nos pudessem conceder um olhar mais aplicado e prático sobre o modo de concretização destas dimensões nas aulas de educação física na escola, designados ao longo do texto por PET. Porque consideramos que a temática abordada poderá ter aplicabilidade universal, o grupo de estudo reunido foi internacional, garantindo, na medida do possível, a pluriculturalidade pretendida.

Tendo em vista a manutenção do anonimato dos seus discursos, as citações a eles feitas ao longo do texto estão identificadas com as três siglas já mencionadas, para reconhecer o grupo de onde provêm, e com uma ordem numérica aleatória.

\section{Recolha e análise preliminar dos dados}

A recolha e análise dos dados foram processos acompanhados e paralelos, permitindo-nos uma permanente comparação, triangulação e interpretação da informação, tornando todo o processo de análise mais sólido, autêntico e consistente $32-34$. Contudo, para que essa triangulação pudesse ser mais eficaz e umas entrevistas pudessem informar as seguintes (havendo uma evolução do processo de reunião do conteúdo do geral para o particular), elas foram realizadas de acordo com uma ordem específica sendo primeiro realizadas as entrevistas aos sujeitos de outras áreas que não as ciências do desporto, seguidamente aos professores e investigadores da área das ciências do desporto e, por fim, aos professores de educação física.

Além de todas as entrevistas terem sido realizadas em locais de conforto para os intervenientes (suas casas, locais de trabalho ou outros sugeridos pelos mesmos), com o objetivo de obtenção de testemunhos genuínos, o papel do entrevistador foi permanentemente empenhar-se na construção de um ambiente favorável, ouvindo atentamente e conduzindo a entrevista adiante ${ }^{35}$.

As entrevistas foram integralmente gravadas e transcritas, para posterior análise. Nesta análise que, por força do conteúdo em causa, foi temática $^{36}$, após leitura repetida e extensiva do conteúdo das entrevistas foram concretizados dois primeiros passos fundamentais:

a) A identificação e divisão do conteúdo em unidades de significado ${ }^{37}$.

b) A identificação de características comuns a essas unidades de significado, emergindo assim as principais categorias a serem analisadas ${ }^{35,37,38}$.

Foi com base nesta organização preliminar do conteúdo que se procedeu à sua análise e discussão, tendo em vista o melhor aproveitamento possível da informação para a sistematização dos frutos essenciais desta investigação.

Porque o mundo é, segundo Sousa Santos ${ }^{38}$, comunicação, sendo-o também a lógica científica pós moderna, através da triangulação entre o conteúdo disponível na literatura específica da área e a informação proveniente das entrevistas realizadas, precedeu-se a uma análise e discussão crítica, interpretativa e compreensiva da temática de investigação, pela comunicação entre as diferentes fontes de informação.

Todo o trabalho e respetivos procedimentos metodológicos foram submetidos à avaliação, análise e aprovação do Comité de Ética da Faculdade de Desporto da Universidade do Porto. 


\section{Resultados e Discussão}

Educar a sensibilidade pela experiência unitária
processo-produto

Sentir é sentir-se a si mesmo ao reflexionar, fruir a sensação do seu próprio estado como sentimento sentido. Experiência de si sempre iniciada e sempre inesperada, é também uma consideração e apreciação inédita do objeto, que desperta e mantém ativa a imaginação. Ambos, sujeito e objeto, aliados no duplo alargamento que constitui a genuína essência do estético - um alargamento de representação do objeto (bem como do sujeito) que está sem dúvida compreendido no juízo de gosto (p.39$40)^{39}$.

Há uma atitude pedagógica sobre a educação física, porventura a predominante, que revela as preocupações típicas de um olhar externo sobre o desporto e, sobretudo, sobre o aluno:

Cada vez mais o nosso olhar sob nós mesmos tem partido de fora, de uma forma de avaliação externa. Eu acho que a educação física, com o conteúdo que já existe, o elemento da cultura corporal, permite recuperar um pouco da nossa sensibilidade, da possibilidade de olhar para nós mesmos e para o outro a partir dessa corporeidade partilhada, sem necessariamente recorrermos a equipamentos materiais de avaliação, como os que agora estão tanto na moda. A ideia de que eu consigo perceber e ser sensível à dor do outro a partir da minha própria dor, da minha própria experiência de dor, por exemplo, é de extremo interesse pedagógico. Para isso é necessário que eu recupere essa capacidade de ouvir e me identificar com o outro (ISS3).

Esta experiência social e partilhada descrita por DEWEY ${ }^{40} \mathrm{em}$ relação à arte parece apresentar também uma importante aplicabilidade à educação física, uma vez que a interação provocada pelas atividades desportivas possibilita aos intervenientes, a partir da sua própria experiência individual, a ampliação e o enriquecimento de uma sensibilidade que é construída de forma partilhada.

Partindo da premissa que o desenvolvimento de uma sensibilidade estético-ética perante o desporto constitui um relevante elemento não só de alargamento ou ampliação do pensar, compreender, viver e experienciar o desporto e a vida, mas sobretudo como mobilizador e disponibilizador da aprendizagem $^{41,42}$, urge procurar desvelar formas concretas de o tornar realizável (OSS5):
Podemos confirmar muita coisa, podemos mo- bilizar-nos para conhecer muita coisa friamen- te. E o resultado é diferente do que quando nos mobilizamos porque nos afetou e nos tocou. Não é por acaso que os jovens ou os estudan- tes, de um modo geral, têm melhores resulta- dos naquilo que apreciam. Nas disciplinas que gostam mais (OSS5).

As a physical educator and coach I think the more important venture is to allow our children to experience aesthetic and ethic excitement in our domain (ISS6).

Deste modo, há perguntas que se impóem. Como educar a sensibilidade através e no desporto? Que competências estético-éticas pretendemos desenvolver nos alunos? Que conteúdos da educação física podem responder a estas inquietaçôes?

É consensual no seio do nosso grupo de estudo que a sensibilidade estético-ética se aprende e se educa. Um olhar sobre a educação física que a equacione como um projeto estético-ético requer, contudo, níveis elevados de envolvimento, engajamento e conhecimento da realidade que se experiencia, de modo a que a pessoa se encontre disponível para os estímulos pedagógicos aos quais é submetida ${ }^{43}$ :

O despertar da sensibilidade para as suas possibilidades é qualquer coisa que tem de ser treinada. Uma pessoa pode saber tudo sobre bons vinhos, e até estudar o assunto... mas tem de experienciar! Tem de desenvolver o gosto e o paladar... (ISS2).

Para um dos nossos entrevistados do ramo artístico, uma educação estético-ética é feita por fases que, contudo, tem que respeitar a natureza global daquilo que se ensina, e exemplifica a sua metodologia no campo do ensino superior da música:

Primeiro o aluno precisa de informação, precisa saber determinadas coisas sobre o tema (...) sobre o compositor, e perceber também o con- 
texto histórico. Depois há toda uma série de aspetos que têm a ver com a própria interpretação que são, por exemplo, questôes físicas, motoras, questões de sonoridade, de ritmo, de sucessão. Toda uma série de aspetos que são necessários trabalhar separadamente, mas que ao mesmo tempo não podem funcionar desligados, têm que funcionar em conjunto. $\mathrm{O}$ nosso papel é depois mostrar ao aluno como estes elementos todos podem ser integrados. Por isso é importante dar o exemplo, mostrar. (...) E, para além disso, é necessário que o aluno desenvolva sentido crítico. Que consiga ouvir o que fez e criticar (OSS2).

Vários dos professores de educação física que integram o grupo de estudo reforçam a importância da observação para construção de uma sensibilidade estético-ética que, segundo LACERDA ${ }^{44}$, não passa apenas por proporcionar momentos de visualização, mas de uma verdadeira educação do olhar, pela qual o aluno observa, analisa, expressa, discute, a sua ação e a dos outros, formulando critérios próprios, autónomos e livres de juízo de gosto, desenvolvendo o sentido crítico, a capacidade de construir ideias e imagens próprias e fundamentá-las:

Quando estou a ver um aluno a correr, gosto de o ver a correr bem e preocupo-me com a amplitude da passada, com os movimentos dos braços, não me preocupo só se ele vai correr muito. (...) Mas isto tem que ser trabalhado, transmitido e desenvolvido nos alunos também (PET1).

Deste modo o aluno não devia terminar a sua escolaridade sem the terem sido dadas oportunidades na educação física de desenvolver competências estético-éticas como

... de criar, compor, avaliar e apreciar... e ter essa noção, portanto, ser capaz de produzir e ser capaz de apreciar, de ver o que os outros fizeram e discutir (ISS2).

Assim, o desenvolvimento do sentido crítico perante as realizações desportivas, requer que se extraiam significados mais ricos a um simples movimento ou ação motora do que os meramente funcionais:

Un passe de voleibol, por ejemplo. Puedes describirlo de manera funcional y biomecânica, para hacerlo bien. Pero luego creo também que se puede interntar enseñarles a apreciar el movimento, el buen movimento, de una manera kinestética (OSS3).

\section{Elementos com potencialidade estético-ética}

The purpose of sport is not producing winners (...) but to be part of something beautiful by pushing their bodies (OSS6).

Como perceber então quais os elementos na educação física que, pela sua contaminação recíproca, podem evidenciar potencialidades para uma educação estético-ética pelo desporto?

A investigação no campo da filosofia do desporto, além de tradicionalmente abordar as questôes estéticas e éticas separadamente, parece revelar, nas últimas décadas, uma preocupação marcadamente superior com a ética do que com a estética, dado que a quantidade de publicações e artigos em revistas e antologias na filosofia do desporto dedicados à ética se verificam expressamente superiores ${ }^{45}$. Neste sentido, na consideração de uma estético-ética da educação física sobressaem com mais facilidade os elementos de conteúdo ético que contaminam a experiência estética na aula. Assim, por exemplo, é fácil e consensual reconhecer que, quando um aluno mais apto num conteúdo se empenha em integrar os seus colegas menos aptos, ajudando-os e trabalhando em equipa, a perceção estética desse momento ou performance parece ficar enriquecida, pela perceção generalizada de uma beleza moral e interesse ético do momento (PET4). O inverso, isto é, a perceção de uma contaminação que a estética pode exercer sobre o conteúdo ético da experiência pedagógica é, aparentemente, mais difícil (ISST). Mas precisamente por ser mais difícil e, porventura, menos comum ou menos tratado, parece-nos que este sentido da retroalimentação estético-ética se apresenta de extrema relevância e merecedor de tratamento, por ser também mais inovador.

Dos elementos que se enquadram no universo estético-ético da educação física sobressai um denominador comum e transversal: a preponderância e valorização do processo, da realização, além do seu produto ou resultado final. Este discurso vai de encontro à ideia de que no desporto não é apenas o produto das habilidades que está em causa, mas o próprio Homem na 
sua experiência e performance corpórea global, no modo como enfrenta os desafios que lhe são colocados e também, naturalmente, no modo como vive, experiencia e atribui sentido ao próprio resultado ${ }^{42,46,47}$.

Deste modo foram identificados pelos entrevistados quatro elementos com uma especial potencialidade estético-ética a ser considerados e abordados na educação física, nos quais a recuperação da experiência unitária processoproduto surge como denominador comum. São eles: a vulnerabilidade, a afetividade, a identidade e a competição.

\section{Vulnerabilidade}

Por permitir espaços amplos de expressão corporal e convocar a atuação da pessoa na sua globalidade, através de uma particular exposição da corporeidade, a educação física pode contrariar a lógica carcerária, prisional e disciplinar em que, segundo FOUCAULT ${ }^{22}$, as escolas modernas se transformaram. Requerendo uma intervenção corporal holística, através de uma particular exposição da corporeidade, esta disciplina coloca o aluno, contudo, numa posição de especial vulnerabilidade, transformando o corpo num palco cénico vulnerável à lei e aos constrangimentos do espaço e da realidade (OSST, OSS5). A abertura à imprevisibilidade e ao risco que grande parte das situações de aprendizagem desportiva impõem, exige do aluno a aceitação, em tempo real, da dúvida sobre a sua capacidade de resposta aos desafios desportivos que lhe são colocados. Esta dúvida permanente sobre o desfecho das atividades e da performance é, segundo a maioria dos nossos entrevistados, um elemento que confere ao desporto em geral um enorme interesse estético e motivacional, na medida em que coloca os indivíduos amarrados ao momento desportivo em permanente suspense e expetativa. Contudo, a condição vulnerável do desportista ou aluno não enriquece apenas o valor estético da experiência, mas também e de forma circular o seu valor ético ${ }^{46}$. É a aceitação de uma condição frágil que tanto interesse estético traz à performance, que exige do aluno não só a humildade para reconhecer e consentir com essa condição, como a retidão de atuação nos momentos em que tal vulnerabilidade o exponha ao fracasso, à derrota e à inferioridade. Funciona também, além disso como motor da luta pelo aperfeiçoamento e melhoria das capacidades e competências do aluno ou desportista, sendo a consciência das nossas limitações o que nos faz procurar superá-las (ISS5).

O desporto, e concretamente a educação física, permite desta forma uma experiência de aprendizagem em mundo que ultrapassa os limites do descritível, do verbalizável, do pensável, do dizível e do previsível. Neste sentido, possibilita a descoberta de outros sentidos que não apenas o de receber conteúdos de aprendizagem, mas expondose, dando-se/concedendo-se vulneravelmente à experiência, também o de viver os acontecimentos sentidos em si e aprender a partir daquilo que nos sucede, nos acontece, que nos toca, que nos afeta e, por isso, nos mobiliza (OSS5). Um corpo vulnerável à experiência é, então, um corpo mais predisposto à aprendizagem, à transformação e ao aperfeiçoamento ${ }^{22}$, podendo neste campo a educação física cumprir um papel que lhe é insubstituível e do qual não se pode furtar.

Neste sentido, a aula de educação física coloca o sujeito entre o treinado e o imprevisível, o planeado e o genuíno, revelando-lhe aspetos da sua forma de estar em mundo que de outro modo permanecem ocultos (ISS3):

No jogo, em alguns momentos, a gente se perde e se comporta ou fala coisas que a gente previamente não elaborou e surgem frases como «Ah! Não sei de onde isso surgiu!", «Não sei como eu fiz isso!» (ISS3).

A disponibilidade para uma aprendizagem na corporeidade que rompa com a postura meramente gnoseológica entre sujeito (aluno) e objeto (conteúdo da aprendizagem) conduz necessariamente à promoção de um tipo de conhecimento involuntário que advém, então, desta exposição à vulnerabilidade:

$\mathrm{O}$ que eu acho interessante, no caso das artes é que com a introdução do corpo, com a apresentação pública do corpo nas artes, fez-se uma outra coisa que foi perceber que há conhecimentos involuntários que podem ser também apresentados. Ou seja, o artista enquanto performer não era o simples ator que reproduzia um determinado texto, era alguém que intervinha num determinado momento, estava vulnerável aos fatores que iriam acontecer, portanto, havia coisas que iriam aparecer que ele não dominava, e isso levava a um conhecimento novo (OSST). 
Ora no desporto não há uma introdução da corporeidade, porque esta representa uma précondição incontornável. Ela não é introduzida, mas simplesmente pré-existe. O caminho a percorrer entre a Zona do Desenvolvimento Atual e a Zona do Próximo Desenvolvimento ${ }^{47}$, corresponde então ao processo que vai do possuir/dominar ao experienciar, acolher, incorporar, sentir e viver o conteúdo desportivo, colocando o sujeito nessa mesma exposição ao incerto, ao imprevisível e, desta forma, a uma condição de aprendizagem vulnerável e de descoberta. Em tal exposição o aluno permite-se à aprendizagem de se deixar conduzir pelo contexto e pelos outros, abrindo-se a um diálogo que transcende as fronteiras daquilo que conhece e domina:

Parte do interesse da ideia de risco no desporto prende-se com a possibilidade de você sair da sua zona de conforto e olhar em volta; de você questionar não só o seu próprio corpo, o seu próprio desempenho, as suas próprias convicções... mas integrar outros elementos que não domina tanto assim... (ISS3).

Transgredir os limites da segurança e do domínio, numa ludicidade entre o sério e o não sério permite, deste modo, que fatores como a emotividade, a ambiguidade e a vulnerabilidade possam emergir e sobressair ${ }^{48}$. Toda a experiência pedagógica tornase, então, mais humana, considerando o aluno não apenas como um executante, mas como um experienciador (OSST):

[Às vezes é preciso] meter areia na engrenagem. (...) Provocarmos uma rutura, não para descarrilar, mas para abrir outras possibilidades e patamares da experiência. (...) Percebendo, por exemplo, como é que a parte emocional pode ser estimulada e ser geradora de conhecimento (OSST).

Em suma, o surgimento de experiências pedagógicas que abram espaço à vulnerabilidade, no desporto como na vida, perante o não domínio, o erro e até o fracasso são, para os nossos entrevistados, de extrema importância:

No es un fin en si mismo, sino que es un medio para aprender, Y se debe utilizar también el valor de fallar, que creo que no se aprecia suficientemente. (...) Hay veces que perdidas, que faltas de êxito, nos enseñan más de nosotros mismos que ganar o dominar (OSS3).

É neste sentido que uma pedagogia da educação física que assegure a devida ênfase e preponderância à completude da experiência, concedendo preponderância ao processo, por oposição à supremacia do produto e do resultado, contribui para uma vivência estético-ética, e por isso mais significativa e enriquecida, do desporto.

\section{Afetividade}

O conhecimento empírico mostra-nos que o desporto tende a ser um fenómeno de atratibilidade universal, mas o que não nos revela com clareza é quais os motivos que conduzem a esta afetação da sensibilidade humana perante o desporto. A teoria de FeEzell ${ }^{46}$ é que o que prende o Homem ao desporto, mais do que as formas ou produtos da sua prática, é o significativo (meaningful) envolvimento que consegue proporcionar entre sujeito e atividade e entre sujeitos, o que por sua vez, contribui para uma vida significativa (meaningfull life).

Para a maioria dos nossos entrevistados, é a ligação afetiva com o desporto que mantém os indivíduos na prática desportiva ao longo da vida. Nesse sentido, o gosto pelo desporto também é algo que se aprende e, consequentemente, que se ensina ou proporciona pedagogicamente (OSS3).

$\mathrm{O}$ envolvimento/engajamento com as atividades desportivas ofertadas na aula de educação física é um dos elementos estéticos com enorme capacidade de contaminação do conteúdo ético do desporto. Tendemos a gostar e envolver-nos nas atividades nas quais sabemos que somos competentes e somos tanto mais competentes quanto mais nos envolvemos (ISS2): "Acho que faltam experiências de sucesso nas aulas de educação física." (ISS3). Deste modo a afetividade com que o aluno se engaja no clima da aula, na situação de aprendizagem, na modalidade desportiva em causa, expressa não só um potencial enriquecimento do conteúdo estético da sua performance, mas também da construção da sua competência e do seu compromisso de superação individual e coletiva na atividade.

Um dos elementos do nosso grupo de estudo sustenta-se na noção de liberdade corporal (embodied freedom) de Merleau-Ponty ${ }^{27}$ para explicar a importância de, na educação física, conseguirmos proporcionar que todos 
os alunos vivam a experiência da competência em corporeidade, isto é, de ser e poder em corpo. A capacidade de se apresentar e expressar corporalmente, de resolver problemas do ambiente a partir de competências corporais e das possibilidades estético-éticas do espaço e do contexto, é algo ao qual a educação física não se pode furtar. Em suma, todo o caminho que vai da inadaptação e desconforto corporal relativamente aos desafios colocados até ao sentimento de liberdade que advém da exploração, experimentação e aquisição de competência, que leva o aluno a sentir e pensar: "I feel free in this environment." (ISS6).

E o primeiro e mais crítico ambiente em que o aluno se envolve é precisamente corpo: através de uma experiência corporal vivida e sentida encontramos formas de

darmos aos nossos alunos noçôes que se transportam para o quotidiano, como o aprendermos a ser em corpo e a gostarmos daquilo que somos. Há alunos que se relacionam mal com o seu corpo e isso tem consequências para a vida. Contribuirmos para resolver isto é fundamental (PET5).

Integrando, então, a componente afetiva, a realização desportiva deixa de representar o mero cumprimento de critérios de eficácia predeterminados, mas a construção de experiências e processos significativos que contribuem para a construção do gosto pelas várias modalidades desportivas. Aprendendo o conteúdo desportivo, o aluno não aprende apenas como fazer algo (uma tarefa, uma técnica ou uma atividade), mas desenvolve formas novas e específicas de percecionar o mundo e a sua forma própria de estar no mundo a partir da realidade que experiencia e aprende ${ }^{49}$. Desta forma, em circunstâncias especiais às quais o desporto é propício, podemos estimular nos alunos um tipo de pensamento executante que, transpondo as fronteiras do mero produto verbalizável da aprendizagem, explora os meandros de uma experiência desportiva vivida, sentida, comprometida (OSS1).

Este é, portanto, mais um campo onde a estética pode contaminar positivamente a ética do desporto, uma vez que sem a ligação afetiva com o desporto este envolvimento numa nova forma de estar e percecionar o mundo perde a oportunidade de emergir:
É a estética que traz à ética a noção de virtude. Se não houver essa noção de virtude, há o mero cumprimento do dever. Tem que haver necessariamente essa relação afetiva (...) porque podemo-nos comportar bem eticamente por interesses mesquinhos... (...) ou até por questôes estratégicas, por exemplo cumprimentar o adversário para dar uma boa impressão ao árbitro [e o gesto não ser genuíno] (ISS2).

Para alguns dos nossos entrevistados, deste modo, na educação física o aluno acede a um tipo de conhecimento que não se limita ao «knowing that» nem tão pouco ao «knowing how», mas que pode atingir o principal foco de qualquer projeto pedagógico, o «knowing to be», isto é, uma forma de ser e estar em desporto que se possa transpor para a vida:

Hay cosas que hay que hacerlos sentir; no es como entender de manera intelectual una ecuación o una fórmula lógica; sino que hay que sentir y entenderlo de una manera vivencial, corporal, sensorial (OSS3).

Assim, se noutras disciplinas escolares o aluno se pode colocar frente ao objeto ou problema de forma distanciada, nas situações de aprendizagem da educação física o aluno não se encontra perante os problemas, mas nos problemas e, por isso, o processo pedagógico não dispensa um envolvimento mais forte e integral do aluno na atividade (ISS2).

Esse envolvimento consolida-se na relação afetiva, na paixão pelo desporto, no deleite e na dor que daí decorrem, na vivência sentimental das aprendizagens desportivas. Estar apaixonado pelo desporto é já uma forma de estar apaixonado pela vida e de cultivar um modo sensível de experienciar o mundo.

\section{Identidade}

Se, numa pedagogia contemporânea, procuramos este envolvimento mais intenso e global do aluno, devendo por isso aprofundar e desenvolver aquilo que é individual, singular, interior e identitário de cada $u^{23,50-52}$, surge a necessidade premente de transposição da lógica funcionalista e produtivista com que ensinamos desporto, abrindo portas à apreciação estético-ética não apenas dos seus resultados e critérios funcionais numericamente mensuráveis, mas também das formas como eles são 
construídos e produzidos, isto é, os seus processos (OSST, OSS1).

Urge, portanto, uma educação física que ponha a descoberto a singularidade e a identidade com que diferentes alunos podem realizar a mesma tarefa, para que descubram não só a natureza de cada modalidade ou atividade desportiva, mas também e sobretudo, a natureza da sua própria corporeidade, isto é, da sua forma própria de viver, expressar e interpretar ${ }^{53}$ a corporalidade e os desafios motrizes que lhes são colocados ${ }^{54}$.

Neste sentido, por exemplo, obedecendo aos critérios técnicos elementares de uma sequência gímnica, o reconhecimento e valorização da diferença e da autenticidade com que cada aluno expressa e vive a sua corporeidade, deve ser descoberto, desenvolvido e promovido em situações de aprendizagem que privilegiem a velocidade e presteza de uns, mas também a serenidade e imperturbabilidade de outros; a potência e o vigor de uns, mas também a leveza e ligeireza de outros, de acordo com aquele que é o estilo e forma de ser e estar em corpo no desporto e na vida (OSS5).

Deste modo, para assegurar a qualidade da experiência desportiva não chega promover no aluno competências de virtuosidade técnica ou de execução, mas também equilibrá-las com capacidades conceptuais, críticas e reflexivas, que contribuam para a formação de cidadãos que não são máquinas, que se questionam, que tomam iniciativa e que agem a partir da sua própria história, das suas emoções, ideias, convicções, liberdade e autonomia (OSST). Neste sentido, não importa apenas o que o aluno faz ou produz, mas também a forma como observa e ajuíza com sentido crítico a realidade ${ }^{55}$, bem como aquilo que ele é e se constrói através da experiência do fazer desportivo, e como se expressa no que faz e produz (OSS3). Assim, o exercício desportivo permite ao aluno

(...) a possibilidade de trabalhar tanto uma técnica ou movimento ao ponto de não ser mais apenas um conjunto de movimentos com um objetivo pragmático, mas passar a ter uma vida própria, imprimindo-lhe um estilo único, que é o seu (...) porque os gestos e os movimentos não dizem apenas do belo, ou do que pode ser belo, mas dizem também de uma mensagem, de uma vivência, de uma implicação sensível única, da sensibilidade que está para além da manifestação exterior de beleza (OSS5).
Este exercício interpretativo da experiência desportiva apresenta-se como um importante fator na promoção do auto-conhecimento, da singularidade e da identidade de cada um, para além do conhecimento do próprio corpo, na medida em que contribui para que o aluno perceba como o «ser em desporto» nos fala de nós, de formas muito sensíveis e intuitivas (ISS3, PET1, PET4):

É interessante que a gente perceba quem somos pelas formas como reagimos e atuamos frente aos outros e frente aos desafios desportivos, e que tomemos consciência de que não estamos prontos ou acabados, que não existe necessariamente um «eu» genuíno e acabado dentro de nós, porque a gente se elabora constantemente, a gente tem oportunidade de elaboração, a gente vai se mostrar a cada momento com essas elaborações (ISS3).

Há, por isso, competências de observação, análise, diálogo, discussão da performance própria e dos pares que podem ganhar espaço na aula de educação física e contribuir amplamente para uma educação do olhar, e da reflexão e do diálogo intersubjetivo estético-ético, pelo reconhecimento da identidade e singularidade de cada um ${ }^{53}$ (PETT; PET4):

Eu faço as avaliações em grupo, portanto os estudantes expóem-se e têm que se expressar perante toda a turma, para que sejam capazes de ver o que fazem, mas também de ouvir os outros falar sobre o que fazem. E só com isso já consigo uma grande dinâmica de pensamento da turma (OSST).

Comunicar as qualidades da performance, própria e dos companheiros, não se esgota num exercício reducionista de enunciação do que está bem e do que está mal, do que é bonito e do que é feio (o que nos situaria demasiado perto de uma atitude produtivista), mas requer a elaboração de juízos de valor estético e ético, fundados no conhecimento objectivo, subjectivo e inter-subjetivo do desporto (reconhecendo-o como um lugar habitado pela alteridade), o que configura o espaço da autonomia, da contingência, da particularidade, do arbitrário.

\section{Competição}

A competição é afirmada, com frequência, não só como elemento chave essencial e predominante 
para a compreensão do desporto, sejam quais forem as formas da sua consideração, mas também para a compreensão do mundo e da sua história evolutiva. Para GILBERT ${ }^{56}$, o problema da lente competitiva com que consideramos o mundo e, em particular, o universo desportivo, é que representa quase sempre um cenário que proporciona muito mais derrotados do que vencedores, sendo por isso, uma lente mais exclusiva do que inclusiva.

Perante o problema do papel da competição na melhoria e desenvolvimento humano, bem como a sua centralidade na compreensão do desporto, alguns filósofos do desporto defendem a consideração da competição como cooperativa, numa procura mutualista pela melhoria e excelência entre os competidores ${ }^{57,58}$. Isto é, apresentandose reciprocamente ao seu mais alto nível, os competidores colaboram mutuamente na melhoria entre si, numa atitude mais cooperativa do que exclusiva ou marginalizadora, permitindo um olhar mais compreensivo e não absoluto sobre o resultado e os critérios de sucesso desportivo.

A procura por outros critérios de sucesso ou excelência que vão para além do resultado competitivo tem o poder de desviar o aluno da primazia do ganhar acima de tudo, despertando-o para o interesse estético da realização, do processo, da fruição e da recriação (OSST e OSS1). Mesmo quando em contexto de rendimento, dominado por valores instrumentalistas e tecnicistas, os desportistas tendem, com frequência, a romper e extrapolar a lógica determinista do desporto, criando e recriando formas de existência social e pessoal para além desses pressupostos pré-determinados ou previstos ${ }^{59}$.

Este aspeto não só contribui para uma experiência estética não linear (ou binária) e mais plural, como contribui para uma lógica ética muito mais integradora e inclusiva do que marginalizadora e exclusiva nas aulas de educação física:

Porque a excelência [e a primazia do resultado] pode excluir. (...) É muitas vezes um mecanismo de exclusão. E o desporto na escola quer ser inclusivo ou exclusivo? (OSS5).

Este olhar para a competição e para os critérios de sucesso no desporto escolar abre a possibilidade, por exemplo, de não só o aluno que faz o Teste de Cooper no melhor tempo da turma possuir reconhecimento, mas também aquele que, durante a corrida, incentivou os seus colegas a continuar até ao fim e dar o seu melhor, quase funcionando como um "pacer» dos seus colegas, ainda que este esforço piore o seu tempo final da corrida.

Com isto não se pretende empequenecer o valor do ganhar e do perder, ou impor uma supremacia do processo relativamente ao produto. Se se reconhece o papel educativo do desporto, então a competição (e consequentemente a questão da vitória e da derrota) tem que ser levada a sério e preparada com cuidado:

Ganhar ou perder numa competição é aquilo que pode vir a acontecer, logo uma competição só é genuína quando isto está em cima da mesa (ISS2).

No entanto este elemento assume por vezes maior preponderância do que a que deveria:

O próprio professor às vezes coloca essa ênfase, perguntando sempre «quanto ficou o jogo? Quanto você correu?». (...) Mas se a ênfase do discurso do professor for na qualidade - no como correu, no que se pode melhorar, no como se sentiu - ou seja aspetos qualitativos da atividade, pode mudar um pouco a forma como se vive ou se vê essa questão da competição (ISS3).

Mais do que atribuir à competição uma natureza final ou última, é importante olhar para este elemento como um meio de superação e transcendência global, coletiva e mutualista (OSS3, ISS3):

Às vezes a competição é apenas uma espécie de combustível (...) um motor para que procuremos fazer melhor (OSST).

Es algo que te motiva (...) porque eso es lo que me permite correr más y más. (...) Es innegable, cuando yo estoy competiendo contra un amigo me esfuerzo más, a veces. Pero para mí no es el ganar por sí mismo, sino que me pide esse esfuerzo mismo que busco. Entonces para mí la cosa sería darle la vuelta a cómo entendemos a nível educativo la competición para decir que esta no es el fin sino es el medio (OSS3).

Neste sentido, para os nossos entrevistados, este olhar mutualista sob a competição une muito mais os intervenientes (competidores) do que os separa, porque empenhando-se em oferecer à competição o 
melhor das suas competências, os alunos trabalham naquilo que $\operatorname{SIMON}^{57}$ define como a mútua procura pela excelência através do desafio competitivo. E é por este motivo que o desporto é uma pedagogia do trato humano, na medida em que o aluno ou o desportista só compete com quem reconhece ser merecedor do seu máximo empenho e competência, com quem se disponibiliza a reconhecer, aceitar e descobrir nas suas capacidades e limitações (ISS5, PETT).

Desta forma, o elemento competitivo que surge como forma de atribuir interesse estético e atratibilidade ao momento desportivo funciona também como contaminador ético fundamental ao mútuo reconhecimento e florescimento de cada um e de todos os intervenientes (OSS5, ISS4), porque

É quando enfrentamos a competição e as dificuldades de superação que procuramos formas mais criativas de ir mais longe (PET2).

Num mundo competitivo, a competição proporcionada nas aulas de educação física pode, assim, não só impulsionar o interesse estético e motivacional das situações de aprendizagem, mas sobretudo, e a partir desse elemento, promover a aprendizagem de uma forma estético-ética de estar no desporto e na vida (PET4).

A consideração da educação física enquanto veículo de educação estético-ética pretende que, através da educação, se desenvolva um modo de estar no desporto que evolua para um modo de estar na vida, verdadeiramente conciliador entre a forma e o ser e, por isso, construtor de uma forma de ser alicerçada numa estético-ética que se transporta do desporto para o dia-a-dia ${ }^{2}$ (OSS5).

BENTO $^{41}$ evidencia que a herança humanista e iluminista que esteve outrora na base da educação física que herdámos e que colocava o homem no centro do ideal educativo foi substituída pelo paradigma produtivista das sociedades industrializadas que privilegia o fazer/produzir ao ser. Perante tal paradigma, no desporto e na vida, em que o valor do fazer assume primazia, urge compreender que o fazer não preenche as possibilidades da educação física, como não o faz, de resto, relativamente a nenhuma disciplina:

(...) a matemática não esgota as possibilidades da matemática. E nunca vai esgotar. Como a língua portuguesa nunca vai esgotar. A literatura nunca vai esgotar. São tudo instrumentos para dar sentido a uma existência, tão enriquecida e humanizada, para poder viver no mundo (ISS1).

A introdução de uma estético-ética na educação física não requer, contudo, uma mudança ou adição de conteúdos, mas uma mudança na forma como encaramos e trabalhamos os conteúdos e, por isso, uma mudança de paradigma que equacione a relação unitária entre processo e produto, quer no desporto, quer na vida. Neste sentido,

Centrar a atenção no processo, e não apenas no resultado, é fundamental. O resultado [no voleibol] é a bola cair dentro do campo adversário, tocar no chão. É uma coisa tão binária quanto isto. Mas há mil formas de isto acontecer (...) (OSS1).

Romper com a lógica meramente funcionalista, binária e determinista com que se encara o conteúdo desportivo permite, então, enriquecê-lo com elementos e significados mais profundos, como a diversidade de formas que o gesto desportivo pode assumir, a criatividade, a singularidade, o prazer, a fruição, o desafio, a descoberta (OSS1).

Colocando o aluno à prova num alargado leque de atividades desportivas, a partir de uma particular exposição e vulnerabilidade corporal, mais do que o desenvolvimento das suas competências motoras e funcionais, a educação física proporciona aos alunos a sua capacidade de adaptação, de auto e hétero conhecimento, de aceitação e superação, em campos que saem fora da sua zona de conforto e principal competência, e nos quais a aprendizagem pode ser muito pertinente (ISS2):

For example, since I am not very tall, I could never be a high level basketball player and I don't have the physical ability to do it, but there is something beautiful and profound in me being able to exercise my own abilities to their maximum. (...) That can be a beautiful experience for me: to be aware of my physical embodiment and my physical causal powers (OSS6).

Então, o valor das tarefas da aula não está apenas em cumpri-las ou no seu resultado ou utilidade, mas sobretudo nas possibilidades de envolvimento, aperfeiçoamento, florescimento, crescimento e libertação que elas proporcionam ao aluno (ISS3, 
ISS4). É nessa medida que um grupo alargado dos nosso entrevistados defende que a riqueza na noção de aperfeiçoamento ou excelência em causa na educação física deve ser considerada muito mais como a arte de viver vulnerável, dando o melhor de si próprio, em caminho de desenvolvimento e melhoramento, do que uma meta, fim/resultado produtivo abstrato ou numericamente mensurável.

A exposição voluntária a estes contextos de vulnerabilidade em prol do potencial transformador que o desporto possui, requerem, contudo, não só a aceitação de tal exposição, mas uma implicação mais íntima e sensível dos alunos, na sua corporeidade, com as matérias de ensino e com o ambiente da aula. Desta forma, ao invés de descorporalizado, meramente observado, assistido e distanciadamente considerado, o desporto é intensamente experienciado ${ }^{60}$. Assim, é a afetividade do aluno com o clima, com os conteúdos e com os intervenientes da aula, que possibilita esta experiência unitária entre processo e produto, de onde sobressaem não apenas os resultados ou frutos mensuráveis da performance, mas sobretudo a qualidade do seu desenvolvimento e a entrega vulnerável aos seus constrangimentos (OSS5).

Por isso, um olhar estético-ético sobre a educação física representa também um olhar estético-ético sobre o aluno, que faz emergir os seus valores e potencialidades internas, a sua identidade e singularidade, para além das suas capacidades produtivas, funcionalistas ou consumistas (ISS4, PETT).

Neste sentido, a redução da experiência desportiva ao binómio vitória/derrota é, antes de mais, desinteressante e aborrecida, pelo que um enriquecimento estético-ético da experiência desportiva pode permitir um maior e mais pertinente sentido ao elemento competitivo:

Estamos realmente obsesionados com la victória. Y esa es una narrativa deportiva muy simple, muy aburrida para mí. (...) Entonces para my hay critérios éticos e estéticos que encuentro mucho más enriquecedores (...) en el que el sentido es que lo que hay que inculcar no es la victoria del equipo en si misma, sino lo que has aprendido al jugar hoy. Por qué te ha importado, por qué no. Por qué has disfrutado y por qué no has disfrutado. No quiere decir que no quieras ganar! Pero la cosa es que tú no quieres ganar si no es de cierta manera, si no es con cierto jugar (OSS3).
É, aliás, responsabilidade do sistema educativo contrariar a lógica binária, predominantemente económica, da sociedade dos nossos dias, que é, antes de mais, inestética, e perante a qual a educação física pode assumir um papel relevante (OSS2, OSS5).

Poderíamos pensar que descentrar a experiência desportiva do seu resultado final vai contra a essência do próprio desporto, que contém na sua natureza constitutiva esta forma de mensuração. Contudo esta questão fica desmistificada, quando o que propomos não é a negação do lado funcional e pragmático do desporto, do seu resultado, mas a quebra da sua primazia exclusiva pelo seu enriquecimento, para que não seja apenas binário, mas possa ser pluriforme, recuperando o sentido da experiência global e unitária entre processo e produto (OSS1, OSS2).

Em suma, integrando estes elementos estéticoéticos, designadamente, a vulnerabilidade, a afetividade, a identidade e a competição, a educação física apresenta-se como uma incubadora natural de experiências estético-éticas, cujo potencial pode ser desperdiçado se não for concretamente contemplado de forma explícita na organização curricular da disciplina (ISS4, PET1 e PET3):

Me parece que los más apropriado es que eso esté formalizado, que esté sistematizado y que haya objetivos claros en función de estos valores estéticos y éticos en la enseñanza (ISS4).

Para vários dos elementos do nosso grupo de estudo, se por um lado o que não está explicitamente descrito na organização curricular dificilmente será didaticamente tratado e abordado, por outro lado, há elementos do universo estético-ético que simplesmente se sentem e experienciam e são de difícil expressão verbal, confirmando a ideia de WitTGENSTEIN de que o que pode ser mostrado não pode ser dito ${ }^{61}$.

O que se propõe, então, não consiste numa mudança de conteúdos, mas antes numa reorientação do foco da ação pedagógica para o sujeito (aluno), encarando e tratando o objeto (a matéria) como experiência potenciadora do seu florescimento (PETT, PET1).

Este florescimento só é possível se encararmos a educação, como defende SAVATER ${ }^{62}$, não apenas a partir de critérios de utilidade, mas sobretudo de critérios de felicidade. Tais critérios requerem que o aluno para além de marcar/ganhar, aprenda a se 
entregar e construir; para além de ver/constatar, aprenda a observar e ajuizar; para além de fazer/ executar, aprenda a experienciar, refletir e atribuir significado; e através deste exercício conquistar novas formas e mais livres de relacionamento com o desporto e com a vida (ISS2, ISS4).

Nesta perspetiva construtiva, quando considerado veículo e oportunidade de florescimento humano, o desporto proporciona uma experiência estéticoética não apenas de superação e melhoramento pessoal, de atingimento de marcas ou records numericamente mensuráveis, mas também e, sobretudo, de libertação humana (PETT, PET1). De veículo para o aperfeiçoamento transforma-se, sobretudo, em experiência libertadora das amarras dicotómicas entre o almejar e o alcançar, o processo e o produto, onde a principal questão deixa de ser binária, para ser o que, através da experiência desportiva, do processo, se aprende sobre nós mesmos e nos faz crescer coletivamente ${ }^{56}$. Neste sentido encontramos na educação física uma forma holística de educação que, por considerar o aluno como "obra em obra" através experiências de alteridade ${ }^{63}$, é mais transformadora do que formatadora, por contemplar o aluno não apenas como executante motor de atividades a quem lhe cabe apenas cumprir, mas também como alguém que, a partir das suas realizaçōes, procura melhores versões de si e dos outros, aprende a entusiasmarse com o sucesso e sofrer com os fracassos, enriquecendo a experiência de forma mais reflexiva, crítica e inquieta, aquilo que alguns dos nossos entrevistados definem como o aprender a ser no mundo e em caminho, em construção.

\title{
Notas
}

a. O termo "desporto", utilizado ao longo deste trabalho traduz uma interpretação abrangente e inclusiva relativamente à generalidade das atividades físicas e desportivas que fazem parte dos conteúdos incluídos na educação física e nas atividades desportivas na escola, referindo-se não só às práticas desportivas formal e institucionalmente regulamentadas de forma exaustiva, mas também a atividades de expressão e exploração motora mais livre e emergentes, como o slackline, as expressóes rítmicas, o tchoukball, ou o parkour.

b. Tradicionalmente, no contexto da filosofia do desporto, a abordagem à estética e à ética é feita de forma independente e separada. Neste trabalho procuramos evidenciar como a sua interdependência se torna relevante, pertinente, e até mesmo incontornável, num olhar pedagógico sobre o desporto. Tal olhar incorpora na educação física elementos de uma perspetivação estético-ética já discorrida por vários filósofos, enquanto espaço de oportunidade a experiências autênticas que reconfiguram a nossa sensibilidade ética, bem como de de experiências de natureza ética que reconfiguram a nossa sensibilidade estética ${ }^{21-23}$. Para melhor esclarecimento sobre as conceções de estética e de ética do autor, bem como da relação de interdependência entre a estética, consultar: ÁviLA DA CosTA L, McNamee MJ e Lacerda $\mathrm{TO}^{24}$.

\begin{abstract}
On the aesthetic-ethic possibilities of physical education

The approximation to aesthetics and ethics in sports' philosophy research usually approaches these two fields of philosophy in a distinct, separate and independent way. Normally greater prominence is given to works in the field of ethics and that can be found in a considerably greater number in the main international journals in this field of study. Considering the aesthetic and ethical potential of sports, largely described in the literature, the purpose of this study is to search for areas of intersection of these fields in an aesthetic-ethical approach of physical education. The methodological framework followed in the pursuit of this purpose included the collecting, analysis and debate based on a hermeneutical and phenomenological perspective of the discourses included in nineteen exploratory semi-structured interviews, with a study group that included teachers/researchers from the areas of aesthetics, ethics, sports and physical education. The confrontation of the content of these interviews with the reflections that were already available in literature enabled us to get as a result an argumentative route that explores the special role of physical education and the relevance of corporeity in the education of the
\end{abstract}


aesthetic-ethical sensibility of students during their educational path. In the conclusions of this route a special emphasis was given to four elements with aesthetic-ethical potential that contribute to an aesthetic-ethics of sport, which recovers the unit of the process-product experience in sports. These elements are the vulnerability, the affection, the identity and the competition, and can be brought from sports into life in the human flourishing route.

KeYwoRDs: Sport; Physical Education; Aesthetics; Ethics; Aesthetic-Ethics.

\section{Referências}

1. Anthony WJ. Sport and Physical Education as a means of aesthetic education. British Journal of Physical Education. 1968;60(179):1-6.

2. Bento JO. À procura de referências para uma Ética do Desporto. In: Bento JO and Marques A, editores. Desporto Ética Sociedade. Porto. Universidade do Porto: Faculdade de Ciências do Desporto e de Educação Física; 1990. p.23-39.

3. Carlisle R. Physical Education and Aesthetics. In: Whiting HTA, Masterson DW, editores. Readings in the Aesthetics of Sport. London: Lepus Books; 1974. p.21-31.

4. Carr D. Aims of physical education. Eur Phy Educ Rev. 1979;2(2):91-100.

5. Carr D. Physical education and value diversity: A response to Andrew Reid. Eur Phy Educ Rev. 1997;3(2):195-205.

6. Green K. Philosophies, ideologies and the practice of physical education. Sport Educ Soc. 1998;3(2):125-143.

7. Kirk D. Physical education, aesthetics and education. Eur Phy Educ Rev. 1984;7(1):65-72.

8. Kirk D. Defining physical education. The social construction of a school subject in postwar Britain. London: The Falmer Press; 1992.

9. Kirk D. Educational value and models-based practice in physical education. Educ Philos Theor. 2013;45(9):973-986.

10. McNamee MJ. Sporting practices, institutions and virtues: A critique and a restatement. J Philos Sport. 1995;22:61-83.

11. McNamee MJ. Education, philosophy and physical education: Analysis, epistemology and axiology. Eur Phy Educ Rev. 1998;4(1):75-91.

12. McNamee M. The nature and values of physical education. In: Green K, Hardman K, editores. Physical education: Essential issues. London: Sage; 2005. p.1-21.

13. Reid LA. Aesthetics and Education. In: Whiting HTA, Masterson DW, editores. Readings in the Aesthetics of Sport. London: Lepus Books; 1974. p.5-20.

14. Reid A. Value pluralism and physical education. Eur Phy Educ Rev. 1997;3(1):6-20.

15. Siedentop D. Sport Education. Champaign (IL): Human Kinetics; 1986.

16. Bento JO. Teoria-prática: uma relação múltipla. In: Mesquita I, Bento JO, editores. Professor de Educação Física: fundar e dignificar a profissão. Belo Horizonte: Instituto Casa da Educação Física; 2012. p.13-48.

17. Graça A. Sobre as questôes do quê ensinar e aprender em educação física. In: Mesquita I, Bento JO, editores. Professor de Educação Física: fundar e dignificar a profissão. Belo Horizonte: Instituto Casa da Educaçáo Física; 2012. p.93-117.

18. Patrício MF. Liçóes de axiologia educacional. Lisboa: Universidade Aberta; 1993.

19. Garcia R, Lemos K. A estética como um valor na educação Física. Rev Paul Educ Fís. 2003;17(1):32-40.

20. Cristino AP da R, Ivo AA, Ilha FRS, Marques MN, Krug HN. A compreensão da estética na formação inicial em Educação Física licenciatura. Lecturas, Educación Física y Deportes. 2008;121(1).

21. Hermann N. Ética e Estética. A relação quase esquecida. Porto Alegre: Edipucrs; 2005.

22. Foucault M. Vigiar e Punir. Nascimento da Prisão. Petrópolis: Editora Vozes; 1999.

23. Schiller F. Sobre a educação estética do ser humano numa série de cartas e outros textos. Tradução, introdução, comentário e glossário de Teresa Rodrigues Cadete. Lisboa: Imprensa Nacional - Casa da Moeda; 1994.

24. Ávila da Costa L, McNamee MJ, Lacerda TO. Physical education as an aesthetic-ethical educational project. Eur Phy Educ Rev. 2015;21(2):162-175.

25. Gagliardini Graça ML, McNamee MJ, Lacerda TO. Sport and circularity between aesthetics and ethics. Rev Port Ciênc 
Desporto. 2012;12:99-102.

26. Cunha e Silva P. O lugar do corpo. Elementos para uma cartografia fractal. Lisboa: Instituto Piaget; 1999.

27. Merleau Ponty M. Fenomenologia da perceção. 3a ed. São Paulo: Martins Fontes; 2006.

28. Gordon D, Parreno P. Zidane a Twenty-First-Century Portrait [filme]. Vaney A, Sighvatsson S, Vaney V, produçáo. Califórnia: Universal International; 2006. 1 filme: 91 min.

29. Carvalho Guerra I. Pesquisa Qualitativa e Análise de Conteúdo. Sentidos e formas de uso. Cascais: Princípia; 2006.

30. Strauss A, Corbin J. Basics of qualitative research: Grounded theory procedures and techniques. Newbury Park (CA): Sage; 1990.

31. Rubin HJ, Rubin IS. Qualitative interviewing: the art of hearing data. Thousand Oaks (CA): Sage; 1995.

32. Seidman IE. Interviewing as qualitative research: a guide for researchers in education and the social sciences. New York: Teachers College; 1991.

33. Boyatzis RE. Transforming qualitative information. Thousand oaks (CA): Sage; 1998.

34. Tesch S. Qualitative research analysis types and software tools. New York: Falmer Press; 1990.

35. Patton MQ. Qualitative evaluation and research methods. Newbury Park (CA): Sage; 1990.

36. Côté J, Salmela JH. A decision-making heuristic for the analysis of unstructured qualitative data. Percept mot skills. 1994;78:465-466.

37. Côté J, Salmela JH, Baria A, Russel SJ. Analysing and interpreting unstructured qualitative data. Sport Psycol. 1993; 7:127-137.

38. Sousa Santos B. Um discurso sobre as ciências. Porto: Ediçóes Afrontamento; 1987.

39. Veríssimo Serrão A. Pensar a sensibilidade. Baumgarten-Kant-Feuerbach. Lisboa: Universidade de Lisboa, Centro de filosofia; 2007.

40. Dewey J. Art as Experience. New York: The Penguin Group; 1934.

41. Bento JO. Desporto. Discurso e Substância. Porto: Campo das Letras; 2004.

42. Lacerda TO. Elementos para a construção de uma Estética do Desporto [dissertação]. Porto: Universidade do Porto, Faculdade de Ciências do Desporto e Educação Física; 2002.

43. Ávila da Costa L, McNamee MJ, Lacerda TO. Physical education as an aesthetic-ethical educational project. Eur Phy Educ Rev. 2015;21(2):162-175.

44. Lacerda TO. Acerca da natureza da experiência estética desencadeada pelo encontro com o desporto e do seu contributo para a educação estética do ser humano. In: Lebre E, Bento J, editores. Professor de Educação Física. Ofícios da Profissão. Porto: Universidade do Porto, Faculdade de Ciências do Desporto e de Educação Física; 2004. p.301-307.

45. Torres C. Furthering Interpretivism's Integrity: Bringing Together Ethics and Aesthetics. J Philos Sport. 2012;39(2):299319.

46. Feezell R. Sport, Philosophy and Good Lives. Lincoln and London: University of Nebraska Press; 2013.

47. Bento JO. Planeamento e Avaliação em Educação Física. Lisboa: Livros Horizonte; 1987.

48. Maffesoli M. Elogio da razão sensível. Petrópolis (RJ): Vozes; 2002.

49. Steel M. What we know when we know a game. In: Galasso PJ, editor. Philosophy of Sport and Physical Activity. Issues and concepts. Toronto: Canadian Scholars' Press Inc; 1988. p.114-122.

50. Luvisolo H. Estética, esporte e educação física. Rio de Janeiro: Sprint; 1997.

51. Nadal E. A Educação Estética. Inovação. 1990;3(1-2):17-27.

52. Read H. A educação pela arte. São Paulo: Martins Fontes; 2001.

53. Arnold P. Educacion física, movimiento y curriculum. 2a ed. Madrid: Ediciones Morata; 1997.

54. Trezzi C. Schiller e Freire: um olhar sobre a educação estética. RECE. 2011;10(1):68-77.

55. Kuntz P. Aesthetics applies to sports as well as to the arts. In: Vanderwerken DL, Wertz SK, editores. Sport inside out. Fort Worth: Texas Christian University Press; 1985. p.492-509.

56. Gilbert B. Competition: Is it what life's all about? In: Galasso PJ, editor. Philosophy of Sport and Physical Activity. Issues and concepts. Toronto: Canadian Scholars' Press Inc; 1988. p.114-122.

57. Simon R. Internalism and internal values in sport. J Philos Sport. 2000;27(1):1-16.

58. Simon R, Torres C, Hager P. Fair Play: The ethics of sport. 4th edition. Boulder CO: Westview Press; 2015. 
59. Silva LMF, Porpino KO. Esporte como experiência estética e educativa: uma abordagem fenomenológica. Holos. 2014;30(5):64-80.

60. Queirós P, Silva P. Pensar o corpo na educação física e no desporto. Implicaçôes éticas para os profissionais. Rev Port Ciênc Desporto. 2012;12:147-150.

61. Wittgenstein L. Tratado lógico-filosófico. Investigaçôes filosóficas. 4a ed. Lisboa: Fundação Calouste Gulbenkian; 2008.

62. Savater F. O valor de educar. Lisboa: Dom Quixote; 2006.

63. Lago C, Vani AC. Experiência estética e educação: um desafio contemporâneo à educação. Impulso. 2015;25(63):5776.

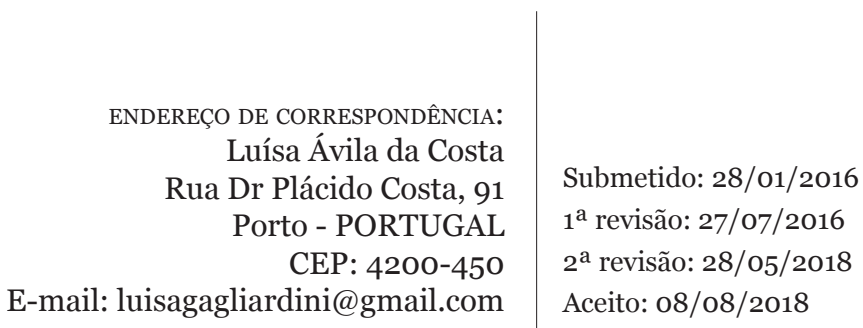

